\title{
A Mathematically Creative Four-Year-Old-What Do We Learn from Him?
}

\author{
Ruti Steinberg \\ Mathematics Education Department, Kibbutzim College of Education, Tel Aviv, Israel \\ Email: rutiste@macam.ac.il
}

Received May $21^{\text {st }}, 2013$; revised June $21^{\text {st }}, 2013$; accepted June $28^{\text {th }}, 2013$

\begin{abstract}
Copyright (C) 2013 Ruti Steinberg. This is an open access article distributed under the Creative Commons Attribution License, which permits unrestricted use, distribution, and reproduction in any medium, provided the original work is properly cited.
\end{abstract}

\begin{abstract}
A 4-year-old child, who is very interested and precocious in mathematics, was interviewed doing mathematical tasks in order to find out how advanced can a 4-year-old child be? His mathematical knowledge and ability are very high. Danny was able to count objects and add them, memorizing many of the addition facts. He was able to check if numbers are even or odd. He solved a variety of challenging addition, subtraction and multiplication problems. He could read and write large numbers in hundreds and thousands and could add large numbers. Analysis was done on the kind of problems the child was able to solve, their level of difficulty and the solution strategies the child used in light of what children usually do to solve these problems in ages 5 - 8 (Carpenter et al., 1999). Danny also showed creativity, including inventing problems for himself to solve and finding mathematical situations in his environment to attend to. An analysis was done on the creative components of his solutions and problem posing using the literature on creativity and creativity in mathematics learning (Leikin \& Pitta-Pantazi, 2013). Interview with his mother showed that she supports Danny's mathematical development by being responsive to his initiations and allowing him to explore his ideas autonomously. Her support was discussed in light of different support patterns of parents and what kind of support is especially beneficial to the child and encourages creativity (Leder, 1992). I discuss implications for education with an emphasis on what kindergarten and school can do to promote problem solving and creativity in mathematics.
\end{abstract}

Keywords: Creativity in Mathematics; Mathematics Education; Early Childhood; Precocious Child in Mathematics

\section{Introduction}

This paper will explore the mathematical world of an unusually talented 4-year-old child (hereafter Danny, not his real name). There is little documentation of mathematically talented children at such a young age so it is valuable to see what we can learn about how this child does mathematics. Danny is a creative and inventive problem solver. I will use his rich mathematical world as a take-off point to discuss the importance of creativity in learning and teaching mathematics. I will also review problem solving in mathematics and its implications for instruction and for enhancing creativity. I will review studies that show that even very young kindergarten children invent creative solution strategies.

The demands of life in the 21 st century will require an ability to apply mathematical thinking in new and changing environments. Children will need to use mathematics flexibly and creatively.

In the interview with Danny I asked him to solve a variety of challenging word problems. I will review and analyze the structure of the problems, their difficulty level and the kind of solution strategies young children typically use to solve them. Some of the review will be given in the section on theoretical background. Some analysis will be in the results section, where each problem that I asked Danny to solve is presented with an explanation of its unique features that will facilitate comparison of Danny's solution methods to what young children usually do. Since Danny solves problems that usually only older children solve, I will compare his solutions to the known strategies of 5 8 -year-old children.

When confronted with an unusual child like Danny, it is inevitable that we ask questions about how he reached such an advanced mathematical level. What interactions between Danny and his family have helped him develop his mathematical thinking? To provide necessary background for this topic, I will review studies about styles of parent-child interactions at home that might enhance or hinder the child's creativity and interest of exploring mathematics (in the discussion section).

\section{Research Goals}

The goals of the study are:

1) Finding out how advanced can a 4 -year-old child be in solving mathematical tasks and what kind of knowledge and strategies the child can develop at this early age;

2) To see if a 4-year-old child can express creative behavior in solving mathematics tasks;

3) To determine what personal traits of the child and what kind of supporting environment allow the child to become so advanced in learning mathematics at such an early age and to 
show mathematics creativity. To draw conclusions about creating supporting environments for children so they can learn mathematics creatively and meaningfully in kindergartens and in schools.

\section{Theoretical Background}

\section{Creativity in Mathematics Learning}

Only in recent years there is an emerging research on creativity in mathematics and not just on creativity as a general trait (Leikin, 2009a). Summaries of this research can be seen in a book (Leikin, Berman, \& Koichu, 2009) and in a special issue of a journal (Leikin, Pitta-Pantazi, 2013). There are many definitions of creativity. I will use a definition of creativity by Torrance (1974) that has been used to build tools to identify creativity and is common in the recent studies on creativity in mathematics (Leikin, 2009a). Torrance suggested four components of creativity: fluency, flexibility, originality and elaboration. Fluency refers to a flow of ideas, "not getting stuck". Flexibility is related to coming up with different ideas, finding more than one solution or solution strategy. Originality means having a unique idea or a solution that is rare or that others haven't thought about. Elaboration means taking it furtherframing a more general or abstract idea or integrating ideas and taking them to the next level. When people commonly think of creativity they think of only the component of originalityproducing different product or process than usual. We see in Torrance's components that there is more to creativity than original ideas. This is especially useful in education and can give tools to advance children towards becoming more creative. In order to be original you also need flexibility and fluency (Leikin, 2009b). In order to produce an idea that is different than others, it is also needed to be different from what you have learned or from your previous ideas.

Milgram and Hong (2009) criticize the common ways to identify gifted children, in many countries, for a special support. These tests are based, many times, only on logical thinking and IQ. Thus, they miss creative children and do not give them the chance to develop their potential fully. Milgram and Hong distinguish between "expert talent" and "creative talent". Expert talent is based on knowledge in the specific field that was acquired by years of studying and working in the area. Creative talent reflects the ability "to produce ideas that are imaginative, clever, elegant, or surprising, beyond analytical thinking" (p. 152).

Leikin (2009b) and Leikin and Lev (2013) consider creativity in school students as "relative creativity" as it is usually related to a new solution for the student for a problem he or she hadn't seen before or to produce original solutions to previously learned problems in the context of the local learning mathematics in school. This is as opposed to inventing new ideas that no one in the world had thought about as professional mathematicians do. Professional mathematicians need to be expert in the previous knowledge, procedures and techniques in mathematics, but they also need to be creative and to connect and integrate ideas, to ask new questions, to use intuition, imagination, and inspiration so they can come up with new knowledge (Ervynck, 1991).

Tabach \& Friedlander (2013) studied creativity of groups of strong students in mathematics from grade 4 to 9 in the same school. The children studied part of their school lessons in separate small groups. They found that, in general, for all three components of creativity, fluency, flexibility and originality, the scores increased with grade level. There was a decrease of creativity in the eighth grade when the students mainly used algebraic equations to solve the problems, but in the ninth grade the students used a more balanced mix of algebra and other solutions. These findings led the researchers to assume "that an increase in mathematical knowledge (i.e. grade level) has the potential to raise the level of creativity as well-with possible exceptions because of the temporary influence of learning a new domain (in our case, algebra). Thus, the observed increase in creativity scores throughout the upper elementary school (Grades 4-6) can be attributed to students' increasing familiarity with the arithmetical domain" (p. 238).

A few studies found correlation of achievement and creativiity among first to fourth graders (Bahar \& Maker, 2011) and first to fifth graders (Sak \& Maker, 2006).

\section{Can Creativity in Mathematics Be Developed?}

There is evidence that it is possible to develop creativity in all students (Sheffield, 2009; Hershkovitz, Peled, \& Littler, 2009). Silver (1997) considered problem solving and problem posing as main tools for the development of the components of mathematical creativity in all students. Fluency can be developed by generating multiple mathematical ideas, multiple answers to a mathematical problem (when such exist), and exploring mathematical situations. Flexibility can be enhanced by generating a few mathematical solutions. Originality can be helped by having children look at many solutions to a mathematical problem and encouraging them to come up with different solutions. Many educators and researchers suggest that creativity is a skill that can be developed. It is important to help all students develop their potential by encouraging creativity from an early age. If we develop creativity even for some of the children we can increase the potential for them to develop in the future new ideas and technologies in science and society.

Efforts should be made in schools to create conditions that will promote creativity for all children. Special attention should be paid to the kind of tasks that are chosen and to educate teachers on ways to promote creativity. Hershkovitz et al. (2009) suggested criteria for good tasks that can encourage school children's creativity. They emphasized the importance of working with children who are at different levels so a good task should allow children to operate at different levels and sophistication. Other criteria they suggest for such tasks are: "Enables multiple solutions; Has different answers or different solution methods; Is challenging even if it can be solved in simple ways; Can be extended by further questions, $\cdots$ Enables generalization and abstraction; Encourages investigation of different cases; Encourages discussion and argumentation; Encourages the use of deep mathematical principles" (p. 259).

Hirsh (2010) suggested to incorporating art activities in mathematics and to explore mathematical, especially geometrical aspects of art in the regular mathematical classes in school to increase creativity among students.

Levav-Waynberg \& Leikin (2012) conducted a teaching experiment with high school students to find out if it is possible to develop creativity in geometry. They worked with regular-high and top-high level classes. They checked the students' creativiity before the experiment on 3 components: flexibility, fluency and originality. An original solution was determined according to its rarity in relation to all the solutions the students gave. 
Before the experiment, many of the students were not able to solve the problems and if they solved them, they usually found one solution. After the teaching experiment all students' flexibility and fluency increased. It was measured by the ability to solve with different strategies and to give different solutions. The top-high students' measures increased more than the regular-high students. At the end students were able to solve more problems correctly and many of them gave 3 solutions or solution strategies to the problems. The originality measure actually decreased at the end. This surprising result is explained by the researchers by the fact that many students now solved in a few ways so it was difficult to come up with a unique solution. The few students whose originality increased were gifted children.

\section{Creativity in Kindergarten Children}

It is reasonable to assume that some components of creativity are not developing easily among young children. This is especially so with the flexibility trait. Young children are known to need to solve problems exactly according to the structure of the problem in "direct modeling" strategies using concrete objects. Their thinking is usually not flexible. For example, they do not see the relationship between addition and subtraction and do not use such a relationship in solving problems (Carpenter \& Moser, 1984; Carpenter, Fennema, Franke, Levi, \& Empson, 1999).

Even so, there is evidence that even kindergarten children can develop components of creativity. Different from the older children, it seems that many young children are strong in the originality trait and it is not so rare. I am referring to originality here in the sense of being able to invent new solution strategies and new ways to solve problems. These ways have not been taught to the child. The criterion I am suggesting here is the child's ability to invent a new solution strategy or procedure, not the criterion that checks if the strategy is different than other children's strategies. We know that certain kind of strategies have been invented by many children. But each child was able to invent himself. It is important to build on this creative thinking of young children and not to direct them to believe later in school that there is only one way to approach a math problem, the way they are taught in school. It is important to promote an environment in the math classroom that will encourage all children to solve problems in a variety of ways and to encourage them to come up with their own unique strategies (Franke, 2003). In the next section on problem solving we will see that kindergarten children and first grade children can develop a variety of invented and novel strategies when solving challenging word problems (Carpenter, Ansell, Franke, Fennema, \& Weisbeck, 1993; Steinberg, 1985a; Warfield \& Yttri, 1999).

Tsamir, Tirosh, Tabach \& Levenson (2010) showed that it is possible to enhance the development of flexibility and fluency among kindergarten children. They gave 5 - 6-year-old kindergarten children a task that can be solved by multiple solutions and solution processes. They gave the children 5 objects in one group and 3 objects in the second group and asked them to make equal groups without adding objects. They gave the task to two groups of kindergarten children from a town with low socio-economic status. The kindergarten teachers of one group participated in a professional development workshop that encouraged them to engage the children in mathematically enriched environments. Project children produced more outcomes and employed more methods than the non-project children. The kindergarten children were flexible enough to employ more than one method. The authors conjectured and brought evidence from studies that the young students, who have had little experience, may be more open and creative in their thinking than older children who got used to standard ways of solving problems in school when one solution and one way of solving is expected.

\section{Problem Solving}

Problem solving in kindergarten and school can be a powerful tool to enhance learning with understanding and to develop creativity in children. The ability to solve problems is very important as a goal in itself. Young children aged $5-8$ are able to solve a variety of challenging problems if they have opportunities to solve problems on a regular basis (Carpenter, Fennema, Franke, Levi, \& Empson, 1999; Carpenter \& Moser, 1984; Fennema, Carpenter, Franke, Levi, Jacobs, \& Empson, 1996). Children who haven't been taught to solve the problems succeed in doing so by applying their skills and understanding in the new situation. Even kindergarten children can solve a variety of challenging word problems with different structures of addition, subtraction, multiplication and division when they are experienced with problem solving (Carpenter, Ansell, Franke, Fennema, \& Weisbeck, 1993; Warfield, \& Yttri, 1999). The young children solve problems with a variety of solution strategies that are very innovative and usually are invented by the children. They use their understanding of natural language, showing sensitivity to the structure of the problem. They are able to find correct solution strategies to different problems. Their solution strategies have different levels of abstraction and sophistication (Carpenter \& Moser, 1984; Carpenter et al., 1999). At the first level the child uses concrete objects to model the math problems. The strategies at this level are called "direct modeling" strategies. The child models the problem exactly by its' structure and does not transform one problem to another. For example, to solve an addition problem with a missing addend such as: Danny has 7 cubes. How many more cubes does he need so he will have 13 cubes? The child solves the problem by adding on objects and not by subtraction. Young children can apply the use of modeling with objects to different problems and they find different correct "direct modeling" strategies. Examples of such strategies on different problems are given in the results section for the problems Danny was asked in the interview.

The second level of strategies is called "counting" strategies (Carpenter \& Moser, 1984; Carpenter et al., 1999). In these strategies the child uses "double counting"- he counts two series simultaneously. For example, to solve $7+4$, the child says 7 and counts (usually with fingers) $8,9,10,11$. The child stops the counting when he shows 4 fingers. The fingers help him see how many steps were used. There are a variety of counting strategies for different problems. The third level of strategies is called "mental strategies"- they are based on memorized facts. Either the child remembers the needed fact or uses known facts to find unknown facts. These strategies are called "derived facts" (Steinberg, 1985a). Example: $6+7$ is $6+$ 6 which is 12 and 1 more.

Young children usually just start to count at age 4 and some of them may count up to 10 . They begin to understand the meaning of the counting (Gelman \& Gallistel, 1978) and they might add very small numbers in a context of a story. We will 
see that the child in this study is very far from a typical 4-yearold.

A number of studies have analyzed the structure of addition and subtraction word problems and their level of difficulty (Riley, Greeno, \& Heller, 1983; Nesher, Greeno, \& Riley, 1982). Dynamic problems that have a verb to describe change are easier than static problems, especially in subtraction. In dynamic problems, the place of the unknown in the number sentence influences the difficulty of the problem. The hardest problems are those with the unknown at the beginning. Carpenter et al. (1999) related the difficulty of the problem to the child's strategy. A missing number at the beginning, for example, is difficult for a child who solves with direct modeling, since he doesn't know what number to start with. More details and explanations are given in the results section in regard to the specific problems that have been used in the interview.

Classes that promote problem solving are those in which the teacher encourages children to solve challenging problems in a variety of ways and explain and discuss their strategies (Fennema, 1996; Franke, 2003; Steinberg, Empson, \& Carpenter, 2004). The teacher builds on the children's thinking in instruction. Socio-mathematical norms are developed in these classes that give children a safe place to take risks and solve problems in their unique ways (Yackel \& Cobb, 1996). These classes are very different than many familiar classes in which the teacher tells the children how to solve problems and they drill the algorithm. To develop creativity in children, it is important to start with environments that promote problem solving at an early age.

\section{Methods and Procedures}

This is a case study with qualitative-descriptive analysis. I conducted an interview with a very bright 4-year-old child to see how he solves mathematical tasks. The child is very advanced for his age in his interest and knowledge of mathematics. The interview was dynamic - the questions and problems I gave the child to solve were decided upon as the interview progressed and as I could see what the child was able to do. There were a few mathematical tasks that the child invented for himself and I went along with them and documented that as well. The interview lasted about 40 minutes and was conducted at the child's home. The interview was videotaped and field notes were taken. The videotape was transcribed and I watched it a number of times so that I could see and notice more details. The child, whom I call Danny (a pseudonym), was focused on the mathematical tasks and was interested in them throughout the interview. (His ability to concentrate on the math tasks for so long is unusual for such a young boy and that allowed me to give him many tasks). The math tasks were in 3 main topics: counting and organizing objects and even and odd numbers, solving word problems and working with large numbers and place value ideas. There were 8 word problems with a variety of addition and subtraction structures of the problems (with numbers that cross to the second ten) and a multiplication problem. The eighth problem was an addition with 2-digit numbers. The problems will be presented and analyzed in the results section.

\section{Results}

In the results section I will present the mathematical tasks and problems that I presented to the child. I will analyze them to show their level of difficulty, the expected "direct modeling" strategy that young children usually use to solve them and the solution strategies that Danny used. I will also describe invented tasks that Danny gave himself. I will add interpretations to the data description.

\section{Inventing Tasks for Himself: "I Wonder How Many Are from Each Color? What If I Add Them?”}

Counting (with objects): I asked Danny: Can you count from 12? He said he counts from 1. Can you count from 28? He didn't answer. What number comes after 28? He answers: 29. And what comes after 29? He answered 30. I took out color plastic chips. He immediately sorted them by color. He started to count the chips in each color group. He counted 10 pink ones and 8 yellow ones. He immediately said: "together they are 18 because 10 and 8 is 18 ." It seems that he remembers the number fact and maybe has a good understanding of adding a number to 10 . He organized 9 blue chips in a line. I asked: How many are the 8 and the 9 together? He immediately answered 17. It appears that he has memorized the number fact. In the next line he counted 7 and dealt with adding 9 and $7 . \mathrm{He}$ didn't recall it from memory and instead counted all the chips and got 16 .

Interpretation: Danny is a very curious young boy. He makes up questions and tasks for himself. He decided to organize the chips by color, to count the number in each group and to add two groups at a time. We will see that this curiosity is characteristic of him throughout the interview. He makes up problems for himself - some of them are very challenging. He was very interested in the activity and didn't wait for me to tell him what to do. We can see that Danny already memorizes addition number facts. He seems to understand adding a number to 10 and shows place value ideas. He can tell the next number after 28 and after 29 . He can go to the next ten easily. He counts objects well most of the time.

\section{More Explorations Danny Creates for Himself_-“Can I Organize the Number in Pairs?”}

Danny continued to invent tasks for himself with a great curiosity for explorations in doing mathematics. He spontaneously started organizing the color groups of chips in pairs. He said-“can I organize 9 chips in pairs?" He made 4 pairs and one. He did that for a few of the colored lines he made before. I asked him if he knows how we call a number that we can put in pairs? He said "2". I told him we call it an even number and we call a number odd if we cannot put it in pairs. I wanted to see how quickly he learns something new and if he can use the new knowledge. I asked him: Is 9 an even number? He answered: "no, one is left over, There are 4 pairs and 1." Is 6 an even number? "Yes. There are 3 pairs." Is 7 an even number? "No. One is left over."

Interpretation: Danny shows his curiosity and love to do math here too by creating explorations for himself. He invents a task-"can I organize the objects that represent different numbers in pairs." He learns very quickly new ideas. He was able to use the new terminology for even and odd numbers right away.

\section{Solving Word Problems}

Danny was asked to solve eight challenging word problems 
with different logical and linguistic mathematical structures. The level of difficulty for the problems increased as he was able to solve the previous problems. I will describe the characteristics of each problem shortly together with a description of Danny's solution strategies.

\section{Problem 1: Simple Dynamic Addition Problem with Sum over 10: In the Kindergarten Backyard There Were 8 Children. Seven More Children Arrived. How Many Children Are There Altogether?}

The problem is a simple addition problem $(\mathbf{8}+7=)$. This is a "dynamic problem" that has a verb, "7 children arrived". The sum of the numbers 8 and 7 is above 10. Danny remembered the answer to the problem and answered 15 immediately without counting.

\section{Problem 2: There Were 7 Children in the Backyard. How Many More Children Need to Come So They Will Be 13 Children in the Back Yard?}

The Problem: This is a "missing addend" addition problem. It is dynamic ("How many children need to come?") which can help a young child understand more easily the "directing instructions in the text" when he or she tries to model the problem with objects. The missing addend is in the middle (asking about the second addend, the number of children that need to come). The number sentence that best describes the problem is $7++_{-}=13$. Most young children (first and second graders) will not solve the problem by subtracting, but will model the problem directly according to the addition structure of the problem. Most children ages $5-8$ use the concrete "direct modeling" strategy to solve this problem ("adding on" strategy) (Carpenter \& Moser, 1984; Carpenter et al., 1999). They take 7 objects and then continue to add objects while counting from 7 , $8,9,10,11,12,13$ and then count the number of objects added and get 6 .

Danny's Solution Strategy: Danny didn't know at first how to approach the problem and it seems that he sees a problem like that for the first time. He said "I don't know". He hesitated for a short time and then he solved the problem by a "counting" strategy (level 2). In this strategy he needs to coordinate "double counting"- one count is the numbers from 8 to 13 and the second count, that is done simultaneously, is the count of the number of adding steps (1-6). Usually, children "double count" by keeping track on their fingers. Danny also used his fingers but in a different way. He didn't count the numbers in sequence. Instead, he kept track of the "double counting" by saying one number from one sequence (8-13) and one number from the second sequence (1-6). He put one finger and said " 7 plus 1 is 8 ". He put 2 fingers and said " 8 plus 1 is 9 " and so on until he got to 6 fingers and the sum 13. He had some difficulty finishing in this way and I helped him and we did it together until he got to the answer 6 (6 fingers).

Interpretation: Danny used a correct "counting" strategy and dealt with the double counting so he can keep track and knows when to stop the counting. His keeping track process is hard to execute since he doesn't say the numbers in sequence 8 , $9,10 \cdots$ but he takes one number from one counting sequence and another number from the second sequence. He needs to remember where he was in each sequence when he comes back to it, which puts a strain on the short term memory. This is a relatively rare keeping track strategy (Steinberg, 1985) and children who use it often get confused in the middle and make errors, since it is so difficult to do. Even though he is using a level 2 "counting" strategy and he does not use a concrete "direct modeling" strategy, still, the structure of the missing addend problem influences his solution. He solves the problem by addition and doesn't transform the problem into a subtraction situation. He tries to follow the story in the problem exactly.

\section{Problem 3: A Multiplication Problem: There Were 3} Groups of Children in the Kindergarten. There Were 4 Children in Each Group. How Many Children Were in All the Groups?

This is a multiplication problem. It is reasonable to assume that Danny has never met a problem like that before. Young children usually solve the problem by directly modeling it with objects or drawing. They make 3 groups, put 4 objects in each one and count them all. Danny didn't use objects. He answered immediately by recalling the multiplication fact from memory (level 3-recall of facts). He said: "3 multiplies $\cdots$ that's 12." I asked what number sentence was he saying and he didn't answer. As he explained his strategy he had solved it in a different way, checking his solution: He said: " $4 \times 2=8$ and 4 more is 12 . He found that by a "counting strategy" (level 2) similarly to how he solved the previous problem with keeping track strategy of one from each sequence. He put up one finger and said: "8 plus 1 is 9", a second finger and said " 8 plus 2 is 10 ", a third finger and said: " 8 plus 3 is 11 ", and a fourth finger and said: " 8 plus 4 is 12 ". I asked him how he knew this is a multiplication problem - he didn't answer.

Interpretation: He understands a multiplication problem. He recognizes that this is a multiplication situation and he knows how to say a multiplication number sentence (even though he said it without finishing his thinking). He knows this multiplication fact from memory. He checks his answer with another solution strategy. He shows flexibility and fluency by coming up with two ways of solving the problem spontaneously. $\mathrm{He}$ is able to change his point of view on the problem and to come up with a different solution strategy.

Problem 4: Subtraction, Start Unknown: There Were a Few Children in the Kindergarten Backyard. We Do Not Know How Many Children Were There. Then, 5 Children Went Inside the Kindergarten and 4 Children Were Left in the Backyard. How Many Children Were at the Backyard at the Beginning?

This is a dynamic subtraction problem (" 5 children went inside"). A number sentence that represents the problem best is: $-\mathbf{5}=\mathbf{4}$. This is a very difficult problem for children who solve problems in a "direct modeling" strategy (level 1) using concrete objects. This problem asks to find out how many children were present initially. Young children who solve the problem using direct modeling strategies have great difficulty modeling the problem, since the unknown is at the beginning. The child doesn't know what objects to start with and how to represent the unknown. At the "direct modeling" level the children are not able to see the relationship between this subtraction problem and an equivalent addition problem, and they do not transform the problem into addition. Many first and second graders are not able to solve the problem at all. The children who solve the problem by "direct modeling" use a "trial and error" strategy. They guess a number to start with (such as 10), 
they subtract 5 from 10 and see if 4 is left. If not, they adjust their guess and try to start with another number. It is unusual to give this problem to young children, definitely at age 4 .

Danny's Solution Strategy and Interpretation: Danny first answered he doesn't know. He was embarrassed. He asked "1?" I suggested for him to try. I repeated the problem. He put down one object and said "it is not 1 ". He put 2 objects and said-no, it is not that 3?-No. 4?? I repeated the problem. I asked if there were 4 children, is it possible that 5 children had left? $\mathrm{He}$ said - no. That seems to help him understand the problem. He continued to add one at a time and checked to see what is left after subtracting 5. Interestingly, he didn't use the objects to do the subtraction. He did all calculations by recall of facts from memory. But he needed to put down the objects so he can think of the number he subtracts from. After he understood the problem, he used a "trial and error" strategy. This strategy is consistent with the structure of the problem - a subtraction problem in which the start is unknown.

\section{Problem 5: A Compare Problem: Danny Has 11 Cubes. His Brother, David has 7 Cubes. How Many More Cubes Does Danny Have than David?}

This is also a difficult problem even for second graders. The idea of comparing two sets and the language involved in it are not easy for children (Carpenter et al., 1999; Riley et al., 1983). There is no verb in the problem (it is static) that could give the child a hint towards how to act out the problem. Many children who use "direct modeling" have difficulty solving the problem, others build the two groups and match them one by one and see how many more counters are in the larger group. Danny first was not sure what the problem is asking. I probed him by: "does he have 1 more? 2 more?" He understood the meaning and solved it with a "derived fact" strategy based on knowing addition facts from memory (level 3). He said: "7 and 3 is 10 . So 7 and 4 is 11 ". He used a known fact ( 7 plus 3 ) to solve an unfamiliar fact -7 plus 4 .

\section{Problem 6: Subtraction Missing Addend Problem: Danny Had 15 Cubes. His Brother, David Took a Few Cubes and 8 Cubes Were Left. How Many Cubes Did David Take?}

This is a subtraction, dynamic problem. The number sentence that represents the problem best is $\mathbf{1 5} \boldsymbol{-}_{\mathbf{C}} \mathbf{=} \mathbf{8}$. A child who uses "direct modeling" takes 15 objects, starts by trial and error to take some counters away and checks if 8 counters are left. Then the child corrects the trials until 8 counters are left. This strategy models the problem by its structure. The child who uses level 1 "direct modeling" strategy doesn't see the relationship between this subtraction problem and an addition problem. Danny did see the connection between addition and subtraction and he transformed the problem into a missing addend addition problem. He said: "8 plus what is 15 ?" It is easier to do the calculation in addition. He solved it with a "counting strategy" with double counting simultaneously, similarly to previous problems: He put one finger and said " 8 plus 1 is 9", 2 fingers- " 8 plus 2 is 10 " all the way to " 8 plus 7 is 15 " and gave the correct answer 7. This keeping track process is very difficult to execute especially with 7 steps (Steinberg, 1985b). Here too, Danny doesn't count continuously in each sequence such as $9,10,11 \cdots$ but needs to go back and forth between the 2 counting sequences $(9-15,1-7)$ and needs to remember where he was in one sequence and where he was in the second sequence.
Problem 7: A Static Subtraction Problem: There Were 12 Cubes. 4 Cubes Were Blue and the Rest of the Cubes Were Yellow. How Many Yellow Cubes Were There?

This is a difficult problem since it is static. There is no verb or change in the problem.

A child who solves the problem by "direct modeling" (level 1) doesn't get cues from the problem of how to act it out with objects. Danny solved the problem immediately in the most surprising and creative way. He understood he needs to subtract 4 from 12 . He connected the subtraction problem to a multiplication problem. He remembers the multiplication fact:

$3 \times 4=12$. Therefore, $12-4=8$. He said: "If 3 times 4 is 12 , I take one 4, so two 4's are left and this is 8 (he remembers how much are two 4's)!!

Interpretation: In the many years that I have interviewed school and kindergarten children on their mathematical thinking I have never seen a child who solved a subtraction problem via a multiplication problem. This is a very original and creative solution. The originality of it is very unique and rare. Of course, it is very unusual that this bright 4-year-old child remembers multiplication facts at this age. Danny understood the problem right away and did not find the static situation difficult. He recognized that he can represent the problem with a subtraction number sentence. He solved it with "mental strategies" (level 3). This strategy is based on memorized number facts. He used "derived facts" in which he used a known multiplication fact $3 \times 4$ to find an unknown subtraction fact $12-4$. This solution is also very flexible. He saw the relationship between multiplication and addition and subtraction. $12-4$ is 3 times 4 minus one four. Two 4's are left and he knows it is 8 by an addition or multiplication fact, 4 and 4 is 8 (or 2 times 4 is 8 ).

\section{Working with Large Numbers and Place Value Knowledge}

I wanted to see Danny's knowledge of large numbers and place value ideas. I asked him how many children are in his kindergarten. He said 23. And how many are in the second kindergarten? He said 31. I dared asking him how many children are in both kindergartens. He said he doesn't know and he had no idea how to calculate the answer. I showed him base-ten manipulatives (from cardboard) that I brought to the interview. These are strips divided into 10 squares for tens and small squares for ones. I asked him to count how many squares are in one strip. He counted 10. I showed him 2 strips and asked how many squares are there? He immediately said 20 . I added a one and after a short hesitation he said it is 21 ! I added another 2 and we counted them together: 22, 23. I told him this shows how many children are in his kindergarten. I asked him to show how many children are in the second class. He took a 10 and said 10 . He took another 10. I asked how many are there and he said 20. I asked how many are 20 and another 10 while giving him the 10 and he said 30. And one more? He said 31. Now I asked how many children are there in both kindergartens? He was not sure what to do and said he doesn't know. I suggested he can count. He looked at it and immediately said 50 pointing to the tens. Then he proceeded to calculate orally without using the 10-blocks. He said 3 and 1 is 4, so it is 54!! (Figure 1).

I asked him if he knows how to write 54 and he wrote it well. I dared asking another problem with the big numbers. I asked: "How many children need to come so we will have 60 children?” He calculated mentally without the blocks. He cleverly 
said 54 plus 5 is 59 , and 1 more is 60 . He wrote a 6 under the 54 and wrote 60 under (Figure 2).

Interpretation: Danny has a lot of knowledge of large numbers and place value ideas. It was remarkable to see how fast he learned to use the new 10-blocks to solve very challenging problems with large numbers. He can count by tens. He didn't need to count the second and third ten by ones, but could see it is 20 and 30 immediately. He could look at 3 10-blocks and 2 10-blocks and know it is 50 without even counting by 10 's. He seems to grasp the idea already that 5 rods of 10 is 50 . He could count on from tens-20, 21, 22, 23. He could add tens and ones separately. To get from 54 to 60 he first added within the same ten - and he could do it mentally -54 and 5 is 59 . Then he saw that just adding one more is 60. It appears that he is familiar with the sequence of the numbers at least through 100 .

The numbers are meaningful for him and he uses them for general knowledge from his surroundings. I assume not too many 4-year-old know how many children are in their class and in the parallel class.

Reading and Calculating with Large Numbers: I asked him to read the following numbers: $124,1335,2034$ - he could read all of them easily. I asked how much is $2034+4$. He answered immediately 2038!!

Inventing Another Problem for Himself: I stopped the interview at this point thinking to myself that the child was so

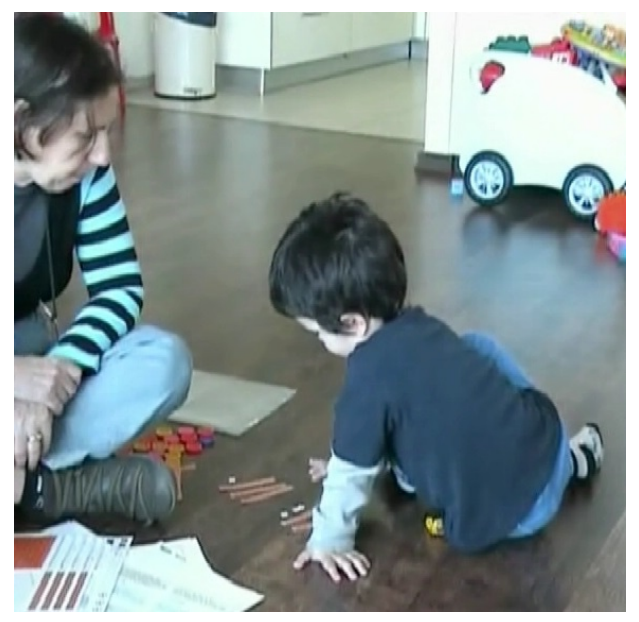

Figure 1.

Using tens and ones manipulatives to solve $23+31$.

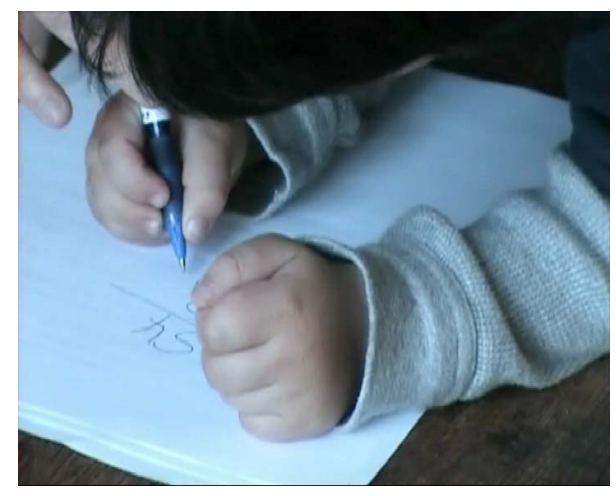

Figure 2.

Danny writes large numbers. concentrated on solving these amazingly difficult problems - he is only 4 ! But it was not enough for Danny. He came up with another invented task for himself. He saw that there are more manipulatives in my kit (a hundred - a square and a thousanda drawing of a cube). To my amazement Danny pointed at the thousand cube and said - this is a thousand. I asked "How do you know"? And he said it looks "a lot" and it is probably a 1000 !! He asked how many are in the square and I said a hundred and I showed him that 10 tens equal a hundred. He created a task for himself-he said, "I wonder how much is a 1000 (taking the cube) plus a hundred (taking the square) and a ten (taking the 10-rod) and a one (taking the one)" (Figure 3). He calculated the numbers mentally. He said: " 1 and a 10 is 11.11 and a 100 is 111 . And another 1000 ? He didn't know how to proceed. I suggested he starts from the 1000 and 100 . He could say it is 1100 . And then he added the 11 and said 1111 . His mom asked him how to write it. First he said 1011 and when she asked him again he corrected himself to 1111 . His mom told him what a unique number it is that all the digits are 1.

Interpretation: Here again Danny shows how quickly he learns new ideas. He has a very good understanding of the structure of the number system. He can read large numbers. He can add a number in the same ten with a large number $(54+5=59)$, can add hundreds and tens $(11+100=111)$ and thousands $(2034+4=2038,1000+100+10+1)$. He can write 2-digit numbers.

Wow. I am totally "blown away". All that was done by a 4year-old child?!! In one sitting!

\section{Discussion}

This study shows that it is possible for a 4-year-old child to do mathematics at a very high level. Danny is able to use mathematical ideas flexibly, with much insight and with a good number sense. He could count and remembers many addition and multiplication facts. When he didn't remember he used "counting" strategies. He has much knowledge of large numbers and place value ideas. He is curious and intrigued by numbers and mathematics and has high motivation. He also learned new ideas during the interview very quickly and was able to use them. Thus, we can see some information on his learning ability while interacting with an adult, what Vygotsky (1978) called "the zone of proximal development".

Problem Solving Ability: Danny solved all 8 word problems with different structures. The problems are very challenging

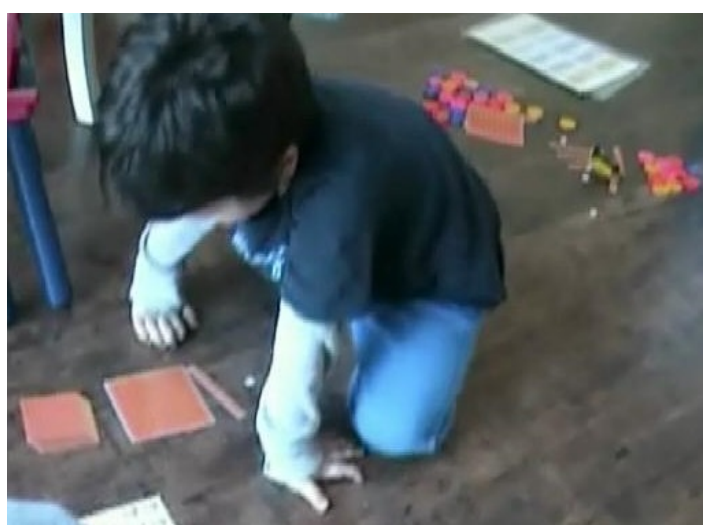

Figure 3.

Showing $1000+100+10+1$ with manipulatives. 
and most of them he saw for the first time. He was attentive to the structure of the problem and to the nature of the language in it. Danny didn't use "direct modeling" (level 1) strategies with concrete objects (which most 5 - 7-year-old children use). He solved the problems with recall of memorized number facts (level 3) or with "counting" strategies (level 2). Still, he was listening carefully to the structure of the problem and typically used strategies that matched the problem. For example, he solved the subtraction problem with the "start unknown" (problem 4) with a trial and error strategy in which he guessed a number to start with and then adjusted it after a check- since he needed a number to start the subtraction process. Modeling the problem according to its structure (even when not using "direct modeling") is a very powerful tool that enables even kindergarten children to solve challenging problems (Carpenter et al., 1993; Warfield \& Yttri, 1999).

Learning to solve challenging word problems should be a major goal of teaching mathematics in kindergarten through elementary school (Carpenter et al., 1999). It is more important than learning to add or to multiply. The children learn to use their mathematical knowledge and skills in new situations in creative ways. This kind of adaptive use of one's thinking is needed in real life and in changing situations. By encouraging kindergarten and school children to be engaged in solving problems and finding their unique solution strategies we enhance creativity in all children (Fennema et al., 1996; Silver, 1997). Even children who solve problems only with "direct modeling" strategies with objects come up with many different and correct invented strategies according to the structure of the problem. Children see that solving a challenging problem can take time, they learn to deal with an uncertain situation and to develop perseverance so they can stick with the difficult problem even when they do not see an immediate solution. This is very important for developing a sense of self confidence in one's ability to solve problems.

Personal Traits That Are Important for Problem Solving Ability: Danny has great interest and motivation to do math (Figure 4). He is also willing to "take risks" and to try to solve new and challenging problems, even when he has never seen problems like that before and is not sure he can solve them. He uses the skills and ideas he already has to tackle the new and unfamiliar problems. Leikin \& Pitta-Pantazi (2013) summarized studies of personality attributes of talented children and found that risk taking to tackle an unfamiliar problem is characteristic of creative children and is one of the traits that promote innovation. Danny also learns fast-there were a few

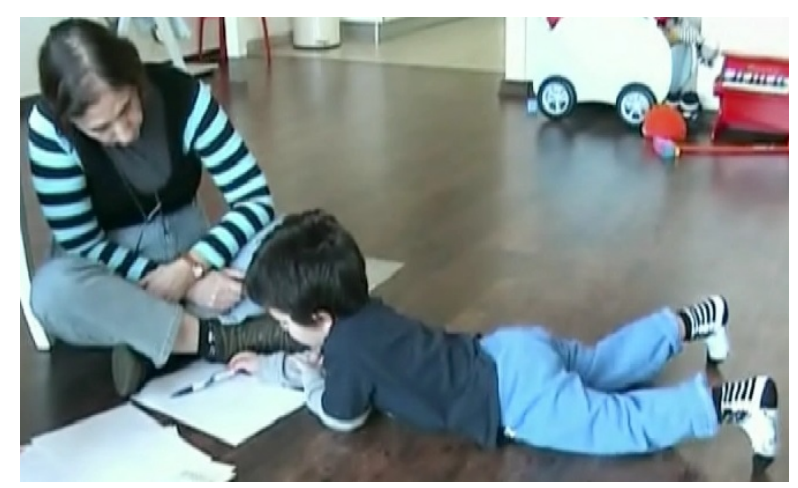

Figure 4.

Danny shows interest and motivation to do math. times during the interview that he learned new ideas and skills and was able to use them immediately. Examples: He learned how to use tens and ones with 10-blocks and learned to add 2-digit numbers with them. He learned about an even number and could immediately check if numbers are even or odd. Danny was also very concentrated on the tasks throughout the interview-it is very unusual for a 4-year-old child.

Creativity: Danny showed a lot of creativity in doing mathematics. Examining Torrance's categories for creativity (1974): Flexibility, fluency and originality in Danny's work we can see many instances in which he shows creativity. Flexibility: While Danny usually solved problems according to their stated structure, he was able to see connections between some problems and to transform one problem into another problem that was easier for him to solve. Thus, he shows flexibility in these solutions. In Problem 6 the given structure was $15-{ }_{-}=8$ but Danny solved by $8+=15$. This requires great flexibility in thinking and seeing the relationship between addition and subtraction. Similarly, he solved $12-4$ in problem 7 by $3 \times 4=12$ and one 4 less is $2 \times 4$. Solving the subtraction problem by a multiplication problem shows great flexibility. Flexibility in solving word problems develops with age. Young children (ages 5 - 7) are usually not flexible in their solution strategies and they model problems exactly by their structure (Fennema et al., 1996). Another example where Danny showed flexibility was when he tried to add $111+1000$ and didn't know how to do it. When I suggested he can start with the 1000, he was able to switch and solve the problem. Fluency: Danny spontaneously solved a problem in two different ways. For example, in problem 3 he knew that $3 \times 4$ is 12 and he checked it by $2 \times 4$ is 8 and 4 more by counting. He played with the numbers and looked for patterns. When he organized objects in color groups and counted and added them, he was able to find another task with the same objects - to organize them in pairs. This playful attitude helped him change view on the same situation and it develops fluency. Originality: Even though Danny is young, he showed originality in doing math. His solution of solving 12 -4 by multiplication is very unique and original. He needed a great deal of mathematical knowledge for that - he had already memorized multiplication facts. Inventing tasks: He invented and explored many mathematical tasks for himself. This shows originality. Examples: "I wonder how many objects are from each color? How many are they together? Can I put them in pairs? I wonder how much is $1000+100+10+1$ ?" By inventing explorations for himself, Danny learns a lot. Many of the situations are very original and unique. Few kindergarten teachers would dare to give him such problems. I recently talked to Danny's mother and she told me he spent hours with a task he invented - to find all multiples of 3 up to 1200 !!!

What Kind of Support Does Danny Get at Home? When I see what Danny is able to do at age 4, 1 am amazed. I wanted to know what kind of support he gets at home. How does he develop his creativity and meaningful sense making at such an early age. His mother is the main person that helps with his math learning; I asked her how he learns mathematics and what kind of interactions or opportunities he has at home. The mother answered that Danny initiates a lot of the activities and tasks by himself and she responds to that and tries to help him pursue his interest. She tries to respond in a way that will allow him to think and to find the answer himself. She usually answers his question with another question. She said: "I was charmed by his world and learned to see things through his very 
mathematical eyes. He is very attentive to his surrounding and asks many questions". Danny showed interest in numbers from a very early age (2). When they were taking an elevator he was attentive to the numbers so they would go up and down the elevator many times so he can see the changing numbers. One time they were in a building with a -1 floor. He was very excited by that and they again went up and down so he can see that -1 comes when they go below 0 . When Danny goes in a car he sees excitedly that the stoplights are numbered and spends much time reading and thinking about these numbers. When his grandparents take him to the zoo, he counts the number of animals in each cage and compares them. We can see that Danny's great curiosity about math is enhanced by the interaction with his mom and family. When I came for the interview there were numbers (including large numbers) hanging on the walls. They count leaves of a flower and how many leaves are left after some fall. They divide a cookie and talk about halves. Danny learned to write the number "one million". He asked his mom and she checked for him how you call a number that has 60 zeroes. Besides his explorations, Danny also gets a lot of drill and practice. He uses games and practice on electronic devices and practices addition, subtraction and multiplication facts as well. So we can see that, in spite of Danny's very early age, he spends many hours learning, exploring and practicing mathematics.

In examining the support that Danny receives from his mother, we can see that she views her role as helping Danny with his ideas, his interests and his ways of solving problems. The mother-child interactions are within a framework of looking at mathematics as a broader tool to explore real life situations and to be engaged in problem solving. Studies show that there are different patterns of parent-child interactions at home when providing assistance in relation to the child's learning of mathematics. On the one hand the parent interaction with the child was "school like" - structured, directing the child to one kind of solution process and answer and controlling the activity. Tiedemann and Brandt (2010) describe such a parent who "expects a specific answer and constricts the possible course of actions for the learner until the latter can give the requested answer". Danny's mother appears to perceive her role in helping Danny with his math learning at the other end of the spectrum as described by a few researchers (Bishop, 2002; Tiedemann \& Brandt, 2010; Sfard \& Lavie, 2005). She was responsive to Danny's thinking and acts, and encouraged him to explore, to come up with his own ideas and to perceive learning mathematics as part of solving problems within broader life situations. Leder (1992) found that such an approach is important for the child's development, especially when the parent poses high cognitive level questions and when he or she encourages the child to be autonomous.

Implications for Education: Kindergartens and schools can play an important role in enhancing all children's ability to learn mathematics meaningfully and with confidence. They can encourage children to be involved with challenging problem solving. Teachers can expect children to solve problems in their own unique solution strategies, to reflect and discuss the solutions and the mathematical ideas and to learn to respect each other's thinking. Teachers can build upon the students' work in instruction. Research reviewed in this article shows that constructivist classes like that develop understanding and creativity among the children (Fennema et al., 1996; Steinberg et al., 2004). Children invent many solution strategies and procedures and are exposed to a variety of solutions (Franke, 2003). This helps them develop flexibility and fluency and more children also suggest original strategies (Silver, 1997). Teachers are surprised to see the richness of the ideas all children bring to class. Class discussions are also very interesting when they build upon children's thinking (Steinberg, Empson, \& Carpenter, 2004). In these classes, students who are very strong in learning mathematics also find challenging problem solving tasks and high level of mathematical ideas and the environment encouraging them to be creative. In these classes children accept the socio-mathematical norms (Yackel \& Cobb, 1996) that solving in a variety of ways is allowed and encouraged.

These classes are very different from most classes we are familiar with all over the world, in which "tell and practice" is the main way of teaching - the teacher or the textbook tells children exactly how to solve and then they practice it. There is usually one way the students are expected to solve math problems and they are not encouraged to deviate from the standard way of doing things. These classes do not encourage problem solving and creativity.

In this paper we had the opportunity to "meet" a very special 4-year-old child who showed us that the "sky is the limit". We can hope that he finds himself in a challenging and motivating classroom that will encourage problem solving and creativity.

\section{REFERENCES}

Bahar, A. K., \& Maker, C. J. (2011). Exploring the relationship between mathematical creativity and mathematical achievement. AsiaPacific Journal of Gifted and Talented Education, 3, 33-48.

Bishop, A. J. (2002). Mathematical acculturation, cultural conflicts, and transition. In G. de Abreu, A. J. Bishop, \& N. C. Presmeg (Eds.) Transitions between contexts of mathematical practices (pp. 193212). Dordrecht: Kluwer Academic Press. doi:10.1007/0-306-47674-6_10

Carpenter, T. P., \& Moser, J. M. (1984). The acquisition of addition and subtraction concepts in grades one through three. Journal for Research in Mathematics Education, 15, 179-202. doi: $10.2307 / 748348$

Carpenter, T. P., Ansell, E., Franke, M. L., Fennema, E., \& Weisbeck, L. (1993). Models of problem solving: A study of kindergarten children's problem-solving processes. Journal for Research in Mathematics Education, 24, 428-441. doi:10.2307/749152

Carpenter, T. P., Fennema, E., Franke, M. L., Levi, L., \& Empson, S. B. (1999). Children's mathematics: Cognitively guided instruction. Portsmouth, NH: Heinemann.

Ervynck, G. (1991). Mathematical creativity. In D. Tall (Ed.), Advanced mathematical thinking (pp. 42-53). Dordrecht: Kluwer.

Fennema, E., Carpenter, T. P., Franke, M. L., Levi, L., Jacobs, V. R., \& Empson, S. B. (1996). A longitudinal study of learning to use children's thinking in mathematics instruction. Journal for Research in Mathematics Education, 27, 403-434. doi:10.2307/749875

Franke, M. L. (2003). Fostering young children's mathematical understanding. In C. Howes (Ed.), Teaching 4- to 8-year-olds: Literacy, math, multiculturalism, and classroom community. Baltimore, MD: Brookes.

Gelman, R., \& Gallistel, C. R. (1978). The child's understanding of number. Cambridge, MA: Harvard University Press.

Hershkovitz, S., Peled, I., \& Littler, G. (2009). Mathematical creativity and giftedness in elementary school: Task and teacher promoting creativity for all. In R. Leikin, A. Berman, \& B. Koichu (Eds.), Creativity in mathematics and the education of gifted students (pp. 255269). Rotterdam: Sense Publishers.

Hirsh, R. A. (2010). Creativity: Cultural capital in the mathematics classroom. Creative Education, 1, 154-161. doi:10.4236/ce.2010.13024

Leder, G. C. (1992). Mathematics before formal schooling. Educational Studies in Mathematics, 23, 383-396. doi:10.1007/BF00302441 


\section{R. STEINBERG}

Leikin, R. (2009a). Bridging research and theory in mathematics education with research and theory in creativity and giftedness. In R. Leikin, A. Berman, \& B. Koichu (Eds.), Creativity in mathematics and the education of gifted students (pp. 383-409). Rotterdam: Sense Publishers.

Leikin, R. (2009b). Exploring mathematical creativity using multiple solution tasks. In R. Leikin, A. Berman, \& B. Koichu (Eds.), Creativity in mathematics and the education of gifted students (pp. 129145). Rotterdam: Sense Publishers.

Leikin, R., \& Lev, M. (2013). Mathematical creativity in generally gifted and mathematically excelling adolescents: what makes the difference? ZDM-The International Journal on Mathematics Education, 45, 183-197.

Leikin, R., \& Pitta-Pantazi, D. (2013). Creativity and mathematics education: The state of the art. ZDM Mathematics Education, 45, 159-166. doi:10.1007/s11858-012-0459-1

Leikin, R., Berman, A., \& Koichu, B. (2009). Creativity in mathematics and the education of gifted students. Rotterdam: Sense Publisher.

Levav-Waynberg, A., \& Leikin, R. (2012). The role of multiple solution tasks in developing knowledge and creativity in geometry. Journal of Mathematical Behavior, 31, 73-90.

doi:10.1016/j.jmathb.2011.11.001

Milgram, R., \& Hong, E. (2009). Talent loss in mathematics: Causes and solutions. In R. Leikin, A. Berman, \& B. Koichu (Eds.), Creativity in mathematics and the education of gifted students (pp. 149-163). Rotterdam: Sense Publishers.

Nesher, P., Greeno, J. G., \& Riley, M. S. (1982). The development of semantic categories for addition and subtraction. Educational Studies in Mathematics, 13, 373-394. doi:10.1007/BF00366618

Riley, M. S., Greeno, J. G., \& Heller, J. (1983). Development of children's problem-solving ability in arithmetic. The Development of Mathematical Thinking (pp. 153-196). New York: Academic Press.

Sak, U., \& Maker, C. J. (2006). Developmental variations in children's creative mathematical thinking as a function of schooling, age, and knowledge. Creativity Research Journal, 18, 279-291. doi: $10.1207 / \mathrm{s} 15326934 \mathrm{crj} 1803 \quad 5$

Sfard, A., \& Lavie, I. (2005). Why cannot children see as the same what grown-ups cannot see as different? Early numerical thinking revisited. Cognition and Instruction, 23, 237-309. doi: $10.1207 / \mathrm{s} 1532690 x \mathrm{xi2302} 3$
Sheffield, L. (2009). Developing mathematical creativity-Questions may be the answer. In R. Leikin, A. Berman, \& B. Koichu (Eds.), Creativity in mathematics and the education of gifted students (pp. 87-100). Rotterdam: Sense Publishers.

Silver, E. A. (1997). Fostering creativity through instruction rich in mathematical problem solving and problem posing. ZDM-The International Journal on Mathematics Education, 29, 75-80. doi:10.1007/s11858-997-0003-x

Steinberg, R. (1985a). Instruction on derived facts strategies in addition and subtraction. Journal for Research in Mathematics Education, 16, 337-355. doi: $10.2307 / 749356$

Steinberg, R. (1985b). Keeping track processes in addition and subtraction. Paper Presented at the Annual Meeting of the American Educational Research Association, Chicago, IIlinois.

Steinberg, R. M., Empson, S. B., \& Carpenter, T. P. (2004). Inquiry into children's mathematical thinking as a means to teacher change. Journal of Mathematics Teacher Education, 7, 237-267. doi:10.1023/B:JMTE.0000033083.04005.d3

Tabach, M., \& Friedlander, A. (2013). School mathematics and creativity at the elementary and middle grades level: How are they related? ZDM-The International Journal on Mathematics Education, 45, 227-238.

Tiedemann, K., \& Brandt, B. (2010). Parents' Support in Mathematical Discourses. In U. Gellert, E. Jablonka, \& C. Morgan (Eds.). Proceedings of the 6th International Conference on Mathematics Education and Society (pp. 428-437). Berlin: Freie Universität Berlin.

Torrance, E. P. (1974). Torrance tests of creative thinking. Bensenville, IL: Scholastic Testing Service.

Tsamir, P., Tirosh, D., Tabach, M., \& Levenson, E. (2010). Multiple solution methods and multiple outcomes-Is it a task for kindergarten children? Educational Studies in Mathematics, 73, 217-231. doi:10.1007/s10649-009-9215-z

Vygotsky, L. S. (1978). Mind in society: The development of higher psychological processes. Cambridge, MA: Harvard University Press.

Warfield, J., \& Yttri, M. J. (1999). Cognitively Guided Instruction in one kindergarten classroom. In J. V. Copley (Ed.). Mathematics in the early years. Reston, VA: NCTM.

Yackel, E., \& Cobb, P. (1996). Sociomathematical norms, argumentation, and autonomy in mathematics. Journal for Research in Mathematics Education, 458-477. doi:10.2307/749877 